\title{
O sofrimento psíquico das mães adolescentes acolhidas institucionalmente*1
}

\author{
Paula O. Miura*2 \\ Leila Salomão de La Plata Cury Tardivo*3 \\ Dora Mariela Salcedo Barrientos*4
}

\begin{abstract}
O objetivo deste estudo foi compreender as experiências emocionais de violência intrafamiliar vivida por mães adolescentes acolhidas institucionalmente. Trata-se de estudos de caso sobre três mães adolescentes institucionalizadas. Observou-se o sofrimento psíquico das adolescentes por meio de diversas situações: gravidez, brigas, fugas de casa, abandono do filho. Considera-se que a violência intrafamiliar afetou o processo de amadurecimento emocional das adolescentes.
\end{abstract}

Palavras-chave: Maternidade na adolescência, instituição de acolhimento, violência intrafamiliar, sofrimento psíquico

\footnotetext{
*1 Parte deste trabalho foi apresentado na VI Convención Intercontinental de Psicología - HOMINIS 2016, em Havana, Cuba, realizada de 11 a 13 de maio de 2016.

*2 Universidade Federal de Alagoas (Maceió, AL, Br).

*3 Universidade de São Paulo - USP (São Paulo, SP, Br).

${ }^{*} 4$ Universidade de São Paulo - USP (São Paulo, SP, Br).
} 


\section{Introdução}

A gravidez na adolescência apresenta um número expressivo mundialmente. $\mathrm{Na}$ atualidade, 7,3 milhões de jovens com idade abaixo de 18 anos todos os anos dão à luz; desse total, 2 milhões correspondem a adolescentes com idade abaixo de 15 anos e $95 \%$ desses partos acontecem em países em desenvolvimento. Nesses países, estima-se que 19\% das adolescentes engravidam com menos de 18 anos (UNFPA, 2013). No Brasil, entre 2000 e 2010, houve uma redução do percentual de adolescentes que dão à luz, de $23,5 \%$ para $19,3 \%$, sendo que $8,7 \%$ se referem a menores de 15 anos e $10,6 \%$ de 15 a 19 anos. No entanto, mesmo com essa diminuição, o número de adolescentes grávidas ainda é alto (Brasil, 2012). Além disso, o maior número de mães adolescentes se encontra nas classes economicamente mais baixas, em famílias com até um salário mínimo (Novellino, 2011).

Este texto, tendo como temática principal a gravidez na adolescência, pretende apresentar os aspectos psicodinâmicos relacionados ao tema, discutir o assunto associando-o à violência intrafamiliar e discorrer sobre as interrupções no processo de amadurecimento emocional do indivíduo que um ambiente não suficientemente bom pode ocasionar, baseado na psicanálise winnicottiana. Por fim, o texto pretende se aproximar da experiência emocional das mães adolescentes que têm uma vida marcada pela violência intrafamiliar, realizando análises e discussões baseadas nos fragmentos de falas e no referencial psicanalítico.

\section{Gravidez na adolescência: aspectos psicodinâmicos}

Blos (1962/1998) e Deutsch (1967/1983) buscaram em seus estudos compreender alguns aspectos psicodinâmicos da gravidez e da maternidade na adolescência motivados pelo grande aumento 


\section{ARTIGOS}

de adolescentes grávidas na década de 1960. Para os autores, a gravidez na adolescência pode estar relacionada com conflitos infantis não solucionados que impedem a elaboração dos lutos da adolescência. Deutsch (1967/1983) observou que as adolescentes grávidas eram moças que atuavam regressivamente em busca do retorno à fase pré-edípica e oral do desenvolvimento.

Desta forma, a adolescente, diante da exigência de amadurecimento e do desesperador sentimento de solidão advindo da separação da mãe, atua de forma compulsiva na tentativa de reviver a união mãe-filha. No nível de concretização dessa fantasia, o parceiro sexual seria apenas um substituto da mãe e a gravidez o restabelecimento da unidade mãe-filha (Deutsch, 1967/1983).

Um outro fator interessante de ser observado na gravidez de adolescentes é a própria condição de adolescer nessa situação. Para Winnicott (1961/2005b), os adolescentes são imaturos e os adultos, além de necessitar reconhecer a "imaturidade" dos adolescentes, terão de acreditar e atuar sua maturidade como nunca. A imaturidade é um elemento essencial da saúde na adolescência. "Só há uma cura para a imaturidade, e esta é a passagem do tempo, e o crescimento em maturidade que o tempo pode trazer" (p. 198).

\section{Violência intrafamiliar: o impacto no processo de amadurecimento}

Adolescentes que vivenciaram situações de violência intrafamiliar desde bebê ou criança acabam por reeditar experiências infantis de maneira muito mais turbulenta e aterrorizante no período da adolescência do que adolescentes que não passaram por esse tipo de situação. Considerando a violência intrafamiliar como

(...) todo ato e/ou omissão praticado(s) por pais, parentes ou responsável em relação à criança e/ou adolescente que - sendo capaz de causar dor ou dano de natureza física, sexual e/ou psicológica à vítima - implica, de um lado, uma transgressão do poder/dever de proteção do adulto e, de outro, uma "coisificação" da infância, isto é, uma negação do direito que crianças e adolescentes têm de ser tratados como sujeitos e pessoas em condição peculiar de desenvolvimento. (Azevedo e Guerra, 1995, p. 36)

Winnicott (1984/2005c) atribui grande importância ao ambiente no processo de amadurecimento pessoal do indivíduo, esse processo somente acontecerá se o ambiente for suficientemente bom, ou seja, se o ambiente fornecer condições favoráveis suficientes para que as necessidades do bebê sejam atendidas; para tanto, precisa da presença da mãe nesse processo ou de alguém que exerça sua função. Nos casos de violência intrafamiliar, podemos 


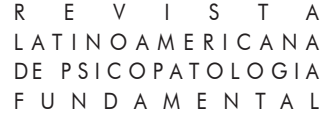

hipotetizar que o ambiente não é suficientemente bom, ou seja, não há condições favoráveis suficientes para atender as necessidades do bebê, ou que o ambiente é mau, onde não há condições favoráveis. Nesses casos, segundo Winnicott (1984/2005b), o ambiente poderia estar impedindo o desenvolvimento do indivíduo, interrompendo a continuidade de ser, considerando que o processo de desenvolvimento e amadurecimento emocional do indivíduo se dá de maneira contínua e constante caso o ambiente possibilite essa continuidade. Desta forma, alguma falha nesse processo pode ter acontecido nos casos de crianças e adolescentes que vivenciaram situações de violência intrafamiliar. Em casos em que as vivências nas relações primordiais são invasivas, intrusivas, a interrupção da continuidade de ser e da espontaneidade podem levar a organizações de defesas primitivas como a cisão. De acordo com Winnicott (1963/1990c), quando a reatividade passa a ser um padrão de comportamento, uma séria interrupção no processo de amadurecimento acontece, impedindo o bebê de tornar-se "uma unidade integrada, capaz de ter um self com um passado, um presente e um futuro" (p. 82). Desta forma, diante de um ambiente tão ameaçador e instável, o falso self se constitui de maneira patológica para defender o verdadeiro self de ser aniquilado pelo ambiente.

Miura \& Tardivo (2015) identificaram uma diferença significativa diante do processo de amadurecimento de adolescentes grávidas que vivenciaram situações de violência daquelas que não vivenciaram. Estas últimas apresentaram recursos psíquicos para lidar com dificuldades ambientais e familiares, com frustrações, com as próprias modificações da adolescência e com a gravidez; nas primeiras os recursos psíquicos que possibilitam a criação e simbolização se apresentaram empobrecidos. No estudo de Pereira et al. (2010), a violência física esteve presente durante a gestação das adolescentes e foi fator preponderante nos casos de depressão identificados nessas jovens.

Winnicott (1960/2005a) expressa que quando o ambiente da mulher grávida não é protetor, mas instável, invasivo, a gestante se tornará mais vulnerável, estando sujeita aos "distúrbios mentais puerperais" (p. 23). Essas condições dificultam a mãe de estar disponível ao bebê e um fracasso dessa função protetora se torna um fator essencial na constituição de uma maternagem não suficientemente boa. Desta forma, a presença acolhedora e protetora de alguém - seja a família, seja o pai do bebê, seja uma instituição de acolhimento - para com a mulher grávida é importante para o desenvolvimento da "preocupação materna primária", estado de sensibilidade exacerbada que inicia-se na gravidez e perdura alguns meses após o parto. A mãe neste estado adapta-se espontaneamente às necessidades do bebê (Winnicott, 1956/2000c). 


\section{ARTIGOS}

Diante do exposto, este trabalho teve como objetivo compreender as experiências emocionais de violência intrafamiliar vivida por mães adolescentes acolhidas institucionalmente.

Este trabalho é um estudo prospectivo, exploratório e descritivo de caráter clínico-qualitativo, que utilizou como método o estudo de caso, bastante adotado por autores que utilizam a psicanálise como referencial teórico (Silva, 2013). O presente estudo foi realizado com três mães adolescentes, entre 13 e 16 anos, acolhidas em instituição dirigida por uma Organização não Governamental. Foram realizadas entrevistas semiestruturadas, individuais, previamente agendadas, em sala tranquila, livre de ruídos e interferência, com duração de aproximadamente 45 minutos, com as pacientes visando conhecer e compreender as experiências, sentimentos e emoções vivenciados pelas adolescentes durante o processo gravídico, bem como suas relações familiares, com o pai do bebê e o vínculo mãe-bebê. Após as apresentações, a entrevistadora pedia para que as adolescentes contassem um pouco sobre a experiência delas na gravidez, e o relato decorria a partir desse ponto inicial. Outros temas relacionados à pesquisa iam sendo perguntados pela pesquisadora conforme a própria fala da adolescente. $\mathrm{O}$ fato de a pesquisadora proporcionar um espaço de escuta e acolhimento foi fundamental para que a entrevista fluísse tranquilamente, permitindo que as adolescentes se expusessem falando de suas experiências.

Após as entrevistas com as adolescentes, cerca de três meses, foi realizada uma entrevista individual com a psicóloga da instituição, a respeito dos casos aqui apresentados. As informações fornecidas por essa profissional contribuiu para que se conhecesse o desenvolvimento das histórias das adolescentes. No momento desta entrevista as jovens já não se encontravam mais na instituição. Foi feita análise de narrativas com base no referencial psicanalítico, principalmente winnicottiano, como uma forma de compreender a experiência de vida narrada pelas adolescentes (Bruner, 1991).

O presente estudo foi apresentado e aprovado pelo Comitê de Ética em Pesquisa do Instituto de Psicologia da USP subordinado tecnicamente à comissão Nacional de Ética em Pesquisa - Ministério da Saúde. ${ }^{1}$ As adolescentes assinaram o Termo de Assentimento e, a direção da instituição, o Termo de Consentimento Livre e Esclarecido. Todos os preceitos éticos de

\footnotetext{
${ }^{1}$ Parecer CEP-IP/USP: 903.934, Parecer SISNEP-CAAE: 31036514.0.0000.5561.
} 


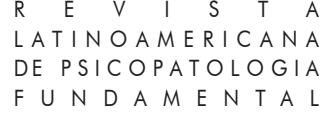

pesquisas com seres humanos foram atendidos conforme resolução n. 466/12 (CNS, 2012).

\section{Resultados e discussão}

\section{História de Gilda ${ }^{2}$}

A adolescente Gilda tem 13 anos e é mãe de Elisa que tem 5 meses. Ela namorava há um ano com Sidney ( 25 anos); engravidou e descobriu que estava grávida no $5^{\circ}$ mês de gestação. Durante o namoro os dois usavam drogas lícitas e ilícitas. Sidney tem mais três filhas com duas outras mulheres. A mãe de Gilda, Silvana, teve cinco filhos, fruto de três relacionamentos. A adolescente é a primogênita e sua mãe tinha 14 anos quando ela nasceu; o pai abandonou sua mãe durante gravidez. A jovem fala do pai com mágoa por nunca ter lhe dado nada (sic), nem bens materiais, nem afeto, ela até chegou a conhecer o pai, mas nunca tiveram relação alguma. Aos 11 anos, Gilda foi espontaneamente morar com a avó materna, por não querer mais presenciar sua mãe sendo agredida pelo seu padrasto. Aos 12 anos iniciou um relacionamento com Sidney, engravidou e isso levou a jovem a mudar-se para a casa do namorado. Moraram juntos por alguns meses, mas se separaram, o que levou Gilda, ainda grávida, a mudar-se, agora, para a casa do tio materno.

A adolescente relatou que só foi perceber a gravidez no $5^{\circ}$ mês de gestação. Ao contar para sua mãe a notícia, diz que esta ficou "feliz", mas preocupada, achando que a filha fosse morrer por ser muito nova.

Com relação ao parto, Gilda descreve esse momento da seguinte forma: O médico falou assim: 'seu parto vai ser normal'. E eu fiquei superdesesperada (...), eu estava supermal porque eu estava com medo também. O médico falou: calma, você vai conseguir ter sua filha. Eu falei: mas eu sou muito nova e eu não sei, não sei o que vai acontecer. Eu fiquei mais de duas horas tentando ter minha filha normal. Eu comecei a ficar com tontura e assim que começou a sair a cabeça dela eu desmaiei. Ai me levaram para a sala de cirurgia e fizeram fórceps, depois que já tinham tirado minha filha, já

\footnotetext{
${ }^{2}$ Com intuito de atender aos preceitos éticos de pesquisas com seres humanos, os nomes aqui utilizados são fíctícios.
} 


\section{ARTIGOS}

tinham me costurado, ai eu acordei e falei: onde é que eu estou, o que eu estou fazendo aqui? Eu estava sem consciência nenhuma. A enfermeira falou: você teve sua filha e ocorreu assim... não correu tudo bem (...). Ela (bebê) não estava reagindo quando ela nasceu porque ela ficou muito tempo presa. Ela não conseguiu reagir, ela não estava respirando, ela não estava com o coração batendo, nada, então os médicos deram choque nela para ver se ela reagia, e foi uma sequência de 15 a 20 choques. E depois disso ela ficou na UTI porque ela não conseguia respirar direito (sic).

Além desse episódio, segundo Gilda, o problema no coração de sua filha também decorreu do uso de drogas que fez durante a gestação. Poucos dias depois da adolescente voltar para casa com sua filha, ela fugiu com a recém-nascida para a casa de sua cunhada. Seu tio e sua mãe a procuraram por dias, chegando a fazer boletim de ocorrência registrando seu desaparecimento, mas ao saber do tumulto, a jovem ligou para a mãe, que solicitou auxílio para o Conselho Tutelar e encaminhou a adolescente para o abrigo; Elisa estava com 2 meses. Sua mãe e seus irmãos vão visitá-las em alguns finais de semana.

A adolescente conta que amamentou Elisa durante quatro meses, mas nunca teve muito leite (sic). A jovem reconhece que não tem paciência, que às vezes grita, bate e não cuida da filha, mas fica brava quando alguma educadora lhe chama a atenção. Já foi chamada para conversar com a Juíza sobre seu comportamento agressivo com a filha e diz que tem medo de perder a guarda dela, pois relata que tenta se controlar, mas não consegue. Na entrevista com a psicóloga, alguns meses após a entrevista com Gilda, a técnica informou que a jovem tinha fugido da instituição e deixado sua filha para adoção.

Discussão do fragmento

$\mathrm{O}$ relato de Gilda aponta para a presença de ambientes familiares que pareceram não ser suficientemente bons, as agressões do padrasto contra sua mãe, o abandono paterno, abandono do companheiro, interrompendo de alguma maneira o processo de amadurecimento da adolescente. Sua avó, seu tio tentaram de alguma maneira acolher a jovem, mas as atuações rebeldes da adolescente não foram acolhidas, o que culminou na institucionalização da mesma. Observa-se que tanto a mãe quanto a filha não conseguem ter uma relação saudável com os parceiros e as relações agressivas e violentas do companheiro da mãe acabam por ter uma forte influência sobre Gilda.

A percepção tardia de Gilda com relação à gravidez parece indicar dificuldade de contato com o próprio corpo, possivelmente em função de suas 


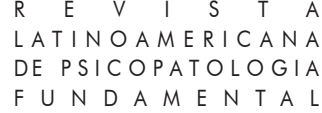

dificuldades psicológicas e também pelo uso de drogas, que parece ter sido prevalente em sua vida. No momento do nascimento da filha, ela vivencia extrema dificuldade, como a dor, o medo e tem um desmaio. Observa-se que Gilda não suportou o momento do parto, em função de fortes angústias, desligando-se da realidade. "O fracasso da mãe-objeto em sobreviver ou da mãe-ambiente em prover oportunidades consistentes para reparação leva a uma perda da capacidade de se preocupar e à substituição por ansiedades e defesas cruas tais como splitting e desintegração" (Winnicott, 1963/1990a, p. 74).

O medo da morte presente na entrevista quando conta da reação da mãe sobre sua gravidez, mostra seu próprio e intenso medo. Gilda demonstrou não ter recursos para se defender e desenvolver sua personalidade. A filha de Gilda deve ter sofrido e estar sofrendo, inclusive pela permanência na UTI e pela enfermidade no coração identificada tanto pelo uso de drogas durante a gestação quanto pelo problema no parto; além disso, mesmo depois do nascimento, a bebê continuou sofrendo com as intrusões, agressões físicas e verbais da mãe adolescente. A jovem mostra que não conseguiu durante seu processo de vida se organizar para dar conta de sua vida e menos ainda de cuidar de uma outra vida. Gilda revela não ter alcançado o amadurecimento para a capacidade de se preocupar, amar e de assumir responsabilidades; diante disso, a jovem acaba por não conseguir cuidar da filha e a deixa para adoção na instituição. Hipotetiza-se que a instituição é sentida inconscientemente por Gilda como uma possibilidade de vínculo estável, confiante, diferente de seu ambiente familiar (instável, violento, inseguro), lugar no qual a adolescente pudesse deixar sua filha.

\section{História de Nubia}

Nubia tem 16 anos e é mãe de Lucas de 7 meses. A adolescente conta que conviveu com a mãe até os 9 meses de vida e nunca mais a viu. Anos depois ficou sabendo que sua mãe havia falecido ainda nova, com cerca de 22 anos, devido ao uso abusivo de drogas. Seu pai também fazia uso de drogas lícitas e ilícitas e não tem mais notícias dele. Ela diz que o início de sua vida foi "uma tragédia" e conta indignada a negligência e o abandono infringido pelos pais. Ela [mãe] me dava até amendoim cru pra comer, você acredita? (sic). Ainda bebê foi adotada por um casal, atualmente aposentado. Conta que tem bom relacionamento com os dois e se arrepende de ter fugido de casa. Durante quase toda a entrevista, Nubia falou dos pais adotivos como sendo seus pais de sangue, apenas no final da entrevista é que contou rapidamente 
sua história com seus pais biológicos. A fala de Nubia durante toda entrevista apresentou uma conotação bastante alegre.

Nubia fugia de casa para ir dançar, pois segundo ela seu pai adotivo não a deixava sair para festas. Nessas fugas, engravidou de seu namorado de 30 anos, que ao saber da gravidez a abandonou. A adolescente conta que quando soube da gravidez nem voltou para casa, foi direto para o Conselho Tutelar, que a encaminhou para uma instituição de acolhimento. Ligou da instituição para sua mãe contando da gravidez, a qual transmitiu a informação ao pai. Estes ficaram muito bravos e acharam melhor Nubia continuar na instituição devido a situação. Eles vão visitá-la de vez em quando, e a jovem sente que eles não estão muito preocupados com ela. Ela diz quando eles ligam para mim, vão logo perguntando do Lucas, nem querem mais saber de mim (sic).

Durante a gravidez até o $7^{\circ}$ mês, Nubia relatou que fugia da instituição para ir às festas dançar. Depois que Lucas nasceu, parou de fugir. $\mathrm{O}$ parto foi cesariana e Lucas nasceu prematuro no $7^{\circ}$ mês de gestação. Aos 7 meses de vida ele ainda estava aquém de seu peso. Nubia diz que não gosta do abrigo, mas acha que é melhor do que ter que morar na rua. Não gosta das regras e limites da instituição e nem das "intrigas" das outras adolescentes. Sente-se estressada, já agrediu educadoras e sente que às vezes desconta no filho, grita com ele, se sente descontrolada e tem medo disso. Também sente que é muita responsabilidade para sua idade cuidar de um filho e tem medo de perdê-lo. Está fazendo tratamento psicológico no CAPS e sente que está ajudando a se controlar mais. Conheceu um rapaz nessa instituição e estão namorando, contou que já tem vários planos para o futuro juntos. $\mathrm{Na}$ entrevista com a psicóloga da instituição, meses depois da com a adolescente, a técnica informou que Nubia fugiu e deixou o filho para adoção na instituição.

Discussão do fragmento

No início de sua história de vida percebe-se um ambiente familiar árido, inóspito, inseguro, uma falta de investimento narcísico das figuras parentais para com Nubia. Suas experiências iniciais foram marcadas por instabilidade e desconfiança, o que pode ter gerado fracassos na organização do eu, com isso tenta se defender não sendo capaz de "sentir culpa, responsabilidade e preocupação de um modo profundo" (Winnicott, 1947/2000b, p. 278).

A imagem registrada por Nubia é da mãe lhe dando amendoim cru, e fica indignada com a falta de cuidados, com a falta de disponibilidade, de sensibilidade para perceber suas necessidades mais básicas e primitivas. $\mathrm{O}$ ambiente 
primordial de Nubia parece não ter possibilitado o amadurecimento da espontaneidade, do verdadeiro self, ao contrário, impossibilitou a continuidade de ser; dessa forma, para sobreviver teve que reagir ao ambiente. Sendo tudo isso vivido numa fase em que o sentimento de self ainda é muito precário, a ruptura da continuidade de ser é vivida como ameaça de aniquilamento. "A alternativa a ser é reagir, e reagir interrompe o ser e o aniquila. Ser e aniquilamento são as duas alternativas" (Winnicott, 1960/1990a, p. 47).

Essa experiência de ameaça de aniquilamento do ser é vivida como angústias psicóticas ou, como Winnicott (1963/1994a) nomeou, "agonias primitivas" sendo essas uma forma de retorno a um estado não integrado; cair para sempre; perda do conluio psicossomático; perda do senso do real, perda da capacidade para relacionar-se com objetos, entre outras maneiras (p. 72).

As agonias primitivas sentidas por Nubia são da ordem do impensável, do irrepresentável, por ter acontecido em uma época pré-verbal, anterior à conquista de um EU unitário. Essas agonias ameaçam o aniquilamento do ser e culminam em uma organização das defesas mais primitivas. Desta forma, para que o bebê possa enfrentar a dor das agonias impensáveis e evitar o aniquilamento organiza suas "defesas que devem precisar reter aspectos primitivos, tais como a cisão da personalidade" (Winnicott, 1970/1994b, p. 201).

Com essa cisão, a constituição do falso self acaba por se dar de maneira patológica tendo como função ocultar o verdadeiro self para evitar seu aniquilamento. $\mathrm{O}$ falso self se constitui como reação ao ambiente e é por meio dele que estabelecerá suas relações falsas por que não espontâneas. Vale pontuar que toda a fala de Nubia parece bastante alegre, mesmo contando episódios difíceis da sua vida, os faz "alegremente". Até a história com sua mãe biológica é contada de maneira entusiasmada. Não percebe-se espontaneidade em sua fala, mas sim uma fala fruto de um falso self sem acesso ou com pouco acesso ao verdadeiro self.

Percebe-se que as relações de Nubia com seu filho - como falta de cuidados e agressão para com ele - são fruto do que vivenciou com sua mãe biológica, expressão do falso self constituído em suas relações primordiais. Sendo o falso self o próprio ambiente de Nubia, é então agressivo, invasivo, negligente para com os outros, reproduz o que vivenciou primitivamente.

Nubia fugiu e não conseguiu se manter com o filho, deixando-o na instituição para adoção. Observa-se a repetição dramática do abandono de uma geração a outra; Nubia abandonada abandona o filho, sendo o trauma psíquico transmitido (Correa, 2003). Esse caso, também, mostra a repetição da violência e negligência de uma geração a outra; ou seja, Nubia sofreu por ser abandonada e não consegue fazer de forma distinta com o filho. Sem ter 


\section{ARTIGOS}

tido possibilidades de conseguir acessar seu verdadeiro si mesmo, expressando-o, falando e elaborando seu sofrimento psíquico, Nubia continuará vivendo o falso self, repetindo sua história traumática.

\section{História de Cristina}

Cristina tem 15 anos e seu filho, Rafael, 6 meses. A adolescente conta que se assustou com a notícia da gravidez. Estava morando na rua e não namorava o pai de seu filho, o qual se comprometeu em assumir, mas "sumiu" (sic). Sua mãe, Aldeci, teve sete filhos de quatro relacionamentos diferentes, estava com 15 anos quando teve seu primeiro filho. Cristina tem dois irmãos mais velhos, um está morando com o avô materno e o outro com o pai. Os 4 irmãos mais novos estão morando com o pai no Estado da Bahia. O pai da adolescente a abandonou ainda bebê.

A jovem chegou a morar na rua ainda criança, por volta de 11 anos. Ela não gostava de seu padrasto, que bebia, se drogava e batia na mãe, que também utilizava substâncias lícitas e ilícitas, por isso perdeu a guarda de seus filhos mais novos para o pai que reside na Bahia. Cristina lembra o episódio onde encontrou seus irmãos com sua mãe num bar, ela estava embriagada e sob efeito das drogas. A jovem levou-a para casa, e lá a mãe teve uma convulsão. Cristina, preocupada com a situação, chamou a polícia e isso acarretou a institucionalização das crianças e a perda da guarda delas para o pai. Cristina ficou um tempo na instituição de acolhimento, mas depois fugiu e passou a perambular pelas ruas e a dormir na casa de amigas; quando não tinha casa para dormir ficava acordada a noite toda. Nessa época, começou a usar drogas, parou quando descobriu que estava grávida, mas continuou fumando durante toda a gestação.

Quando Cristina ficou grávida, contou para a mãe, mas esta não tinha condições de abrigá-la, com isso, a adolescente foi para uma instituição de acolhimento. Diz não se adequar muito às instituições, pois sempre foi acostumada a viver "solta", sem regras e limites, mas por causa do filho fica na instituição, porque é um lugar onde tem tudo para criar meu filho (sic). Atualmente, sua mãe está com outro companheiro, do qual a adolescente gosta, pois ele cuida da mãe, a está ajudando a parar de beber e de fumar. O casal vai mudar para uma casa maior e com melhores condições, isso criou expectativas em Cristina de poder voltar para a casa da mãe.

Quanto ao nascimento do filho, teve parto normal e amamentou assim que ele nasceu. Diz gostar do filho, mas às vezes perde a paciência e grita com ele, de qualquer forma, acha que tem mais paciência com ele do que com 
outra criança. Durante toda entrevista, Cristina parecia distante, não demonstrou expressões diferentes ao contar sobre os diversos episódios de sua vida. Por fim, na entrevista com a psicóloga da instituição, esta informou que Cristina fugiu levando o filho junto, mas não sabe seu paradeiro.

Discussão do fragmento

A adolescente anda pelas ruas, sem rumo; tenta de alguma maneira ajudar sua mãe, que não conseguiu manter a guarda de nenhum dos sete filhos, provavelmente, devido ao consumo de álcool e outras drogas. O ambiente instável, sem pessoas confiáveis parece ter sido o berço das relações primordiais da adolescente, desta forma, para sobreviver teve que reagir a esse ambiente o que impossibilitou sua continuidade de ser e o amadurecimento de sua espontaneidade, sobressaindo o desenvolvimento de um falso self patológico para proteger o verdadeiro self imaturo, frágil.

Durante a entrevista, a jovem pareceu distante, amortecida pelas inúmeras violências sofridas desde criança. Quando indagada do que gosta de fazer, não soube responder, mas quando a mesma pergunta é repetida responde, eu gosto de pintar pano de prato, mas não gosto de desenhar (sic). Desenho exige criatividade, espontaneidade, atributos que parecem ter sido impossíveis de se desenvolver em um ambiente familiar e extrafamiliar (rua) tão inseguro e ameaçador. Diante de todas as fragilidades vividas, Cristina não consegue perceber sua história de violência, ou melhor, parece tê-la "esquecido" defensivamente. Ao ser indagada sobre o que tinha the marcado positivamente na sua vida, responde (...) pra mim foi tudo; e marcado negativamente, ela pergunta e responde $O$ que não me marcou? Ah, não sei. Parece ter a sensação que suas experiências deixaram algum registro, mas devido ao pouco acesso ao seu verdadeiro self, sente tudo isso de maneira confusa. Daí também o sentimento de irrealidade e a falta de contato com sua realidade interna.

$\mathrm{O}$ vazio de sentidos e de sensações também são observados na relação de Cristina com seu filho. Ela repete várias vezes que gosta dele, mesmo sem mudar sua expressão facial, o que pode ser indicativo de sua dificuldade na capacidade de expressar o amor e de se vincular. Essa capacidade parece que ainda não foi desenvolvida pela adolescente, ela apresenta impulsos agressivos não integrados, e os atua no comportamento com o filho e com o outro, o que aponta para uma reprodução de sua história. Ou seja, observase a atuação do falso self patológico em detrimento do verdadeiro, sendo o falso self o próprio ambiente agressivo, inóspito, negligente vivenciado por 


\section{ARTIGOS}

ela. Cristina diz que não quer repetir sua história com o filho, mas diante de suas experiências, da constituição do falso self para defender o verdadeiro self de ser aniquilado, se a adolescente não tiver possibilidades de acessar o verdadeiro self, bem como de elaborar e representar seu sofrimento psíquico, poderá continuar atuando e perpetuando sua história de violência.

\section{Considerações finais}

Com este estudo pôde-se observar que as experiências de violência intrafamiliar - abandono materno, paterno, violência física, negligência vivenciadas pelas adolescentes ainda na infância, interromperam em algum momento o processo de amadurecimento dessas jovens, que clamaram e possivelmente continuam solicitando um espaço para que possam reexperienciar esse amadurecimento que lhes faltou.

A adolescência como um momento de intensas transformações, acabou por ser palco de atuações e reedições mais evidentes como a experiência da gravidez. Cada uma lidou com a experiência da união mãe-filha(o) à sua maneira, com seus poucos recursos. Nenhuma delas pareceu ter conseguido simbolizar, elaborar, ressignificar o sofrimento psíquico carregado das experiências de violência intrafamiliar e que são a todo momento atuados, os quais devem ser percebidos pelo outro, seja este a família, a instituição, o psicólogo, como um pedido de ajuda das adolescentes. Ao saber um pouco mais sobre seus sofrimentos, pela via da simbolização, as adolescentes têm a oportunidade de começar a viver sua história como verdadeiras protagonistas.

Agradecimentos: À Fundação de Amparo à Pesquisa do Estado de São Paulo (Fapesp) pela concessão de uma bolsa de pós-doutorado que possibilitou a realização deste trabalho.

\section{Referências}

Azevedo, M. A., \& Guerra, V. N. A. (1995). Violência doméstica na infância e na adolescência. São Paulo, SP: Robe Editorial.

Blos, P. (1998). Adolescência: uma interpretação psicanalítica. São Paulo, SP: Martins Fontes. (Trabalho original publicado em 1962).

Brasil. (2012). Saúde Brasil 2011: uma análise da situação de saúde e a vigilância 
da saúde da mulher. Brasília: Editora do Ministério da Saúde.

Bruner, J. (1991). The narrative construction of reality. Critical Inquiry, 18, 1-21.

Correa, O. B. R. (2003). Transmissão psíquica entre as gerações. Psicologia USP, 14(3), 35-45.

Deutsch, H. (1983). Problemas psicológicos da adolescência: com ênfase especial na formação de grupos. Rio de Janeiro, RJ: Zahar. (Trabalho original publicado em 1967).

Figueiredo, L. C. (2009). As diversas faces do cuidar: novos ensaios de psicanálise contemporânea. São Paulo, SP: Escuta.

Macedo, M. M. K. et al. (2012). Adolescência e psicanálise. In M. M. K., Macedo, (Org.), Adolescência e psicanálise: intersecções possiveis. Porto Alegre, RS: EdiPUCRS.

Mc Intyre, J. K., \& Widom, C.S. (2011). Childhood victimization and crime victimization. J. Interpers. Violence, 26, 640-63.

Miura, P. O., \& Tardivo, L. S. L. P. C. (2015). A violência intrafamiliar em adolescentes grávidas: reflexões sobre a história de vida e aspectos psicodinâmicos. Relatório de Pesquisa. Fundação de Amparo à Pesquisa do Estado de São Paulo - Fapesp, Brasil.

Moraes, A. A. de R. E. de. (2005). A contribuição winnicottiana para a teoria e clínica da depressão. (Tese de Doutorado). Pós-Graduação em Psicologia Clínica, Pontifícia Universidade Católica de São Paulo.

Novellino, M. S. F. (2011). Um estudo sobre as mães adolescentes brasileiras. Physis Revista de Saúde Coletiva, 21(1), 299-318.

Pereira, P. K. et al. (2010). Complicações obstétricas, eventos estressantes, violência e depressão durante a gravidez em adolescentes atendidas em unidade básica de saúde. Rev Psiq Clín, 37(5), 216-22.

Sachs-Ericsson, N. et al. (2011). Childhood Abuse and current Health Problems among Older Adults: The mediating role of Self-Efficaccy. Psychology of Violence, 1(2), 106-20.

Silva, D. Q. da. (2013). A pesquisa em psicanálise: o método de construção do caso psicanalítico. Estudos de Psicanálise, 39, 37-46.

Tardivo, L. S. L. P. C., \& Pinto Junior, A. A. (2010). Inventário de frases no diagnóstico de violência doméstica contra crianças e adolescentes. São Paulo, SP: Vetor.

UNFPA (2013). Maternidade precoce: enfrentando o desafio da gravidez na adolescência. New York: UNFPA. Recuperado de <http://www.unfpa.org.br/ Arquivos/swop2013.pdf>.

Winnicott, D. W. (1975). O brincar: a atividade criativa e a busca do Eu (Self). In $O$ 


\section{ARTIGOS}

brincar e a realidade (pp. 79-93). Rio de Janeiro, RJ: Imago. (Trabalho original publicado em 1971).

Winnicott, D. W. (1990a). Teoria do relacionamento paterno-infantil. In $O$ ambiente e os processos de maturação (pp. 45-50). Porto Alegre, RS: Artes Médicas. (Trabalho original publicado em 1960).

Winnicott, D. W. (1990b). A integração do ego no desenvolvimento da criança. In O ambiente e os processos de maturação (pp. 55-61). Porto Alegre, RS: Artes Médicas. (Trabalho original publicado em 1962).

Winnicott, D. W. (1990c). Da dependência à independência no desenvolvimento do indivíduo. In $O$ ambiente e os processos de maturação (pp. 79-87). Porto Alegre, RS: Artes Médicas. (Trabalho original publicado em 1963).

Winnicott, D. W. (1990d). O desenvolvimento da capacidade de se preocupar. In O ambiente e os processos de maturação (pp. 79-87). Porto Alegre, RS: Artes Médicas. (Trabalho original publicado em 1963).

Winnicott, D. W. (1994a). O medo do colapso (breakdown). In C. Winnicott, R. Shepherd, M. Davis (Orgs.), Explorações psicanalíticas (pp. 70-76). Porto Alegre, RS: Artmed. (Trabalho original publicado em 1963).

Winnicott, D. W. (1994b). A experiência mãe-bebê na mutualidade. In C. Winnicott, R. Shepherd, M. Davis (Orgs.), Explorações psicanaliticas (pp. 195-202). Porto Alegre, RS: Artes Médicas. (Trabalho original publicado em 1970).

Winnicott, D. W. (2000a). A defesa maníaca. In Da pediatria à psicanálise: obras escolhidas (pp. 199-216). Rio de Janeiro, RJ: Imago. (Trabalho original publicado em 1935).

Winnicott, D. W. (2000b). O ódio na contratransferência. In Da pediatria à psicanálise: obras escolhidas (pp. 277-87). Rio de Janeiro, RJ: Imago. (Trabalho original publicado em 1947).

Winnicott, D. W. (2000c). A preocupação materna primária. In Da pediatria à psicanálise: obras escolhidas (pp. 399-405). Rio de Janeiro, RJ: Imago. (Trabalho original publicado em 1956).

Winnicott, D. W. (2005a). O relacionamento inicial entre uma mãe e seu bebê. In $A$ família e o desenvolvimento individual (pp. 21-8). São Paulo, SP: Martins Fontes. (Trabalho original publicado em 1960).

Winnicott, D. W. (2005b). Adolescência: transpondo a zona de calmaria. In $A$ família e o desenvolvimento individual (pp. 115-127). São Paulo: Martins Fontes. (Trabalho original publicado em 1961).

Winnicott, D. W. (2005c). O conceito de indivíduo saudável. In Tudo começa em casa (pp. 105-114). São Paulo, SP: Martins Fontes. (Trabalho original publicado em 1984). 


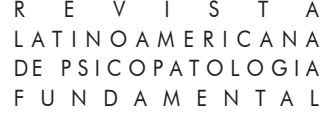

Winnicott, D. W., \& Britton, C. (1999). Tratamento em regime residencial para crianças difíceis. In Privação e delinquência (pp. 59-86). São Paulo, SP: Martins Fontes. (Trabalho original publicado em 1947).

\section{Resumos}

(The psychic suffering of institutionally sheltered adolescent mothers)

The aim of this study was to understand the emotional experiences of intrafamily violence experienced by sheltered adolescent mothers. This paper presents three case studies on sheltered adolescent mothers. The psychological suffering of the adolescent girls was observed through their accounts of several situations: pregnancy, fights, runaway episodes, and abandonment of their child. This study suggests that intra-family violence affected the adolescents' emotional maturation process.

Key words: Maternity in adolescence, shelter, intra-family violence, psychological suffering

(La détresse psychologique des mères adolescentes internées dans des institutions)

Le but de cette recherche était de comprendre les expériences sentimentales de violence familiale vécue par des mères adolescentes internées dans des institutions. Il s'agit de trois études cas de mères adolescentes internées dans des institutions. Leur détresse psychologique résultait de différentes situations : grossesse, bagarres, fuite de la maison parentale, abandon d'enfant. Nous concluons que la violence familiale a affecté le processus de maturation émotionnelle de ces adolescentes.

Mots clés: Maternité à l'adolescence, institution d'accueil, violence familiale, détresse psychologique

(El sufrimiento psíquico de las madres adolescentes acogidas institucionalmente)

El objetivo de este estudio fue comprender las experiencias emocionales de la violencia familiar, vivenciadas por las madres adolescentes aceptadas institucionalmente. Se trata del estudio de caso de tres madres adolescentes institucionalizadas. Se observó el malestar psicológico de las adolescentes en diferentes situaciones: embarazo, peleas, fuga del hogar y abandono del hijo. Se considera que la violencia doméstica afecta el proceso de maduración emocional de las adolescentes.

Palabras clave: Maternidad en la adolescencia, institución de acogida, violencia doméstica, malestar psicológico

Rev. Latinoam. Psicopat. $\overline{\text { Fund., São Paulo, }}$ 20(2), 331-348, jun. 2017 


\section{ARTIGOS}

(Die psychische Belastung institutionell betreuter minderjähriger Mütter)

Ziel dieser Studie war es, die emotionale Erfahrung häuslicher Gewalt von institutionell betreuten jugendlichen Müttern nachzuvollziehen. Zu diesem Zweck wurden drei Fallstudien analysiert. Die psychische Belastung der jungen Mütter zeigte sich in verschiedenen Situationen, wie z.B. Schwangerschaft, Streitsituationen, Ausreißen, Aufgabe des Kindes. Wir kommen zum Schluss, dass häusliche Gewalt den emotionalen Reifeprozess der Jugendlichen beeinträchtigt.

Schlüsselwörter: Mutterschaft von Minderjährigen, betreuende Institution, häusliche Gewalt, psychische Belastung

（收容所里未成年母亲的精神痛苦）

这项研究的目的是理解收容所里未成年母亲所经历过的家庭暴力和精神痛 苦。我们对收容所的三个未成年母亲的案例进行研究, 她们都经历了不同情况 下的精神痛苦：怀孕，吵架，离家出走，遗弃亲子。我们认为，家庭间暴力影 响青少年的情感成熟过程。

关键词: 未成年产妇, 收容所, 家庭间暴力, 精神痛苦。

Citação/Citation: Miúra, P. O., Tardivo, L. S. P. C., \& Barrientos, D. M. S. (2017, junho). O sofrimento psíquico das mães adolescentes acolhidas institucionalmente. Revista Latinoamericana de Psicopatologia Fundamental, 20(2), 331-348. http://dx.doi.org/10.1590/ $1415-4714.2017 \mathrm{v} 20 \mathrm{n} 2 \mathrm{p} 331-8$

Editores do artigo/Editors: Profa. Dra. Ana Maria Rudge e Profa. Dra. Sonia Leite

Recebido/Received: 19.10.2016/ 10.19.2016 Aceito/Accepted: 15.12.2016 / 12.15.2016

Copyright: (C) 2009 Associação Universitária de Pesquisa em Psicopatologia Fundamental/ University Association for Research in Fundamental Psychopathology. Este é um artigo de livre acesso, que permite uso irrestrito, distribuição e reprodução em qualquer meio, desde que o autor e a fonte sejam citados / This is an open-access article, which permits unrestricted use, distribution, and reproduction in any medium, provided the original authors and sources are credited.

Financiamento/Funding: Pesquisa financiada pela Fundação de Amparo à Pesquisa do Estado de São Paulo - Fapesp / The research was funded by Fundação de Amparo à Pesquisa do Estado de São Paulo - Fapesp. Processo n. 2013/09458-0.

Conflito de interesses/Conflict of interest: As autoras declaram que não há conflito de interesses / The authors have no conflict of interest to declare. 


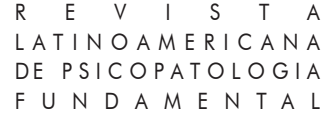

\section{Paula Orchiucci Miura}

Professora do Instituto de Psicologia da Universidade Federal de Alagoas (Maceió, AL, $\mathrm{Br})$.

Av. Lourival de Melo Mota, s/n - Tabuleiro do Martins 57072-970 Maceió, AL, Br.

paula.miura@ip.ufal.br

\section{Leila Salomão de la Plata Cury Tardivo}

Professora Associada do Instituto de Psicologia da Universidade de São Paulo - USP (São Paulom SP, Br).

Av. Professor Mello Moraes, 1721 - Cidade Universitária - Butantã 05508-030 São Paulo, SP, Br

tardivo@usp.br

\section{Dora Mariela Salcedo Barrientos}

Professora Doutora da Escola, Artes e Ciências Humanas da Universidade de São Paulo USP (São Paulo, SP, Br).

Rua Arlindo Béttio, 1000 - Ermelino Matarazzo

03828-000 São Paulo, SP, Br.

dorabarrientos@usp.br the original authors and sources are credited. 